\title{
Eficácia e pH de caldas de glifosato após a adição de fertilizantes nitrogenados e utilização de pulverizador pressurizado por $\mathrm{CO}_{2}$
}

\author{
Saul Jorge Pinto de Carvalho(1), Virginia Damin ${ }^{(2)}$, Ana Carolina Ribeiro Dias ${ }^{(1)}$, Gaspar Miura Yamasaki(1) \\ e Pedro Jacob Christoffoleti ${ }^{(1)}$
}

\begin{abstract}
(1)Universidade de São Paulo (USP), Escola Superior de Agricultura Luiz de Queiroz (Esalq), Departamento de Produção Vegetal, Avenida Pádua Dias, no 11, Caixa Postal 09, CEP 13418-900 Piracicaba, SP. E-mail: sjpcarvalho@yahoo.com.br, anacarolina.r.dias@gmail.com, miurayamasaki@yahoo.com.br, pjchrist@esalq.usp.br (2)USP, Esalq, Departamento de Solos e Nutrição de Plantas. E-mail: virginiadamin@gmail.com
\end{abstract}

\begin{abstract}
Resumo - Este trabalho foi desenvolvido com o objetivo de avaliar a eficácia e o $\mathrm{pH}$ de caldas de glifosato após a adição de fertilizantes nitrogenados e utilização de pulverizador pressurizado por $\mathrm{CO}_{2}$. Em campo, foram aplicadas duas doses de glifosato $\left(360 \mathrm{e} 720 \mathrm{~g} \mathrm{ha}^{-1}\right)$, isoladas ou combinadas a duas concentrações de ureia $\left(2,5\right.$ e 5,0 $\left.\mathrm{g} \mathrm{L}^{-1}\right)$ ou sulfato de amônio $\left(7,5\right.$ e 15,0 $\left.\mathrm{g} \mathrm{L}^{-1}\right)$. Em laboratório, mensurou-se o pH de caldas de glifosato após o uso de diferentes concentrações do produto e dos fertilizantes nitrogenados e após a utilização do pulverizador pressurizado por $\mathrm{CO}_{2}$. Em todas as avaliações do experimento em campo, a menor dose de glifosato teve maior eficácia biológica após a adição de sulfato de amônio $\left(15 \mathrm{~g} \mathrm{~L}^{-1}\right)$ à calda. A ureia $\left(5 \mathrm{~g} \mathrm{~L}^{-1}\right)$ proporcionou efeitos benéficos somente na avaliação aos 28 dias após a aplicação. Em laboratório, o aumento da concentração de glifosato promoveu gradativa acidificação da calda de pulverização, com estabilização do $\mathrm{pH}$ da solução em 4,5. O sulfato de amônio causou pequena acidificação da calda herbicida, enquanto a ureia não alterou o $\mathrm{pH}$. $\mathrm{O}$ uso do pulverizador pressurizado por $\mathrm{CO}_{2}$ pouco alterou o $\mathrm{pH}$ da calda de glifosato. A maior eficácia do glifosato após a adição de fertilizantes nitrogenados à calda está pouco relacionada com alterações no $\mathrm{pH}$ da solução.
\end{abstract}

Termos para indexação: absorção, acidificação, calda herbicida, dessecação, sulfato de amônio, ureia.

\section{Efficacy and $\mathrm{pH}$ of glyphosate spray solutions after the addition of nitrogen fertilizers and the use of $\mathrm{CO}_{2}$-pressurized sprayer}

\begin{abstract}
This work was developed with the objective of evaluating the efficacy and the $\mathrm{pH}$ of glyphosate spray solutions after the addition of nitrogen fertilizers and the use of $\mathrm{CO}_{2}$-pressurized sprayer. In field conditions, two rates of glyphosate ( 360 and $720 \mathrm{~g} \mathrm{ha}^{-1}$ ) were applied either alone or combined with two concentrations of urea $\left(2.5\right.$ and $\left.5.0 \mathrm{~g} \mathrm{~L}^{-1}\right)$ or ammonium sulfate $\left(7.5\right.$ and $\left.15.0 \mathrm{~g} \mathrm{~L}^{-1}\right)$. In laboratory, the $\mathrm{pH}$ of the glyphosate solutions was measured after using different concentrations of the product and nitrogen fertilizers and after using a $\mathrm{CO}_{2}$-pressurized sprayer. For all field condition evaluations, the lowest glyphosate rate had higher biological efficacy after the addition of ammonium sulfate $\left(15 \mathrm{~g} \mathrm{~L}^{-1}\right)$ to the spray solution. Urea $\left(5 \mathrm{~g} \mathrm{~L}^{-1}\right)$ promoted benefits only at the $28^{\text {th }}$-day evaluation. In laboratory, the increase of glyphosate concentration promoted gradual acidification of the spray solution, which stabilized at $\mathrm{pH}$ 4.5. Ammonium sulfate caused minor acidification of the herbicide solution, whereas urea did not change the $\mathrm{pH}$. The use of $\mathrm{CO}_{2}$-pressurized sprayer had small effect on the solution's $\mathrm{pH}$. Highest glyphosate efficacy identified after the addition of nitrogen fertilizers has little relation with changes on the solution's $\mathrm{pH}$.
\end{abstract}

Index terms: absorption, acidification, herbicide spray, desiccation, ammonium sulfate, urea.

\section{Introdução}

O glifosato [N-(fosfonometil)glicina] é um herbicida não seletivo, de ação sistêmica, usado no controle de plantas daninhas anuais e perenes e na dessecação de culturas de cobertura (Rodrigues \& Almeida, 2005; Timossi et al., 2006). Ele inibe a enzima enol piruvil shiquimato fosfato sintase (EPSPS), que participa da síntese dos aminoácidos aromáticos fenilalanina, tirosina e triptofano. Em água, tem comportamento de ácido fraco, com quatro constantes de dissociação (pKa): <2,0, 2,6, 5,6 e 10,6 (Coutinho \& Mazo, 2005).

$\mathrm{O}$ pKa é o valor de $\mathrm{pH}$ no qual $50 \%$ das moléculas de um ácido fraco estão na forma molecular e 50\% na forma dissociada. Quando o $\mathrm{pH}$ de determinada solução excede em uma unidade o pKa do ácido fraco, considerase que $90 \%$ das moléculas estão na forma favorecida pela alteração do pH (Christoffoleti \& López-Ovejero, 2005). 
No caso do herbicida glifosato, quando o $\mathrm{pH}$ do meio tem valores entre 3,6 e 4,6, a forma predominante de suas moléculas possui duas cargas negativas (Coutinho $\&$ Mazo, 2005).

Tanto o pH da solução como a presença de cátions na água de pulverização têm importância prática na ação herbicida do glifosato. Em geral, a adição de cátions monovalentes $\left(\mathrm{NH}_{4}{ }^{+}, \mathrm{K}^{+} \mathrm{eNa}{ }^{+}\right)$à calda do glifosato resulta em maior eficácia biológica, enquanto cátions bi $\left(\mathrm{Ca}^{2+}\right.$, $\mathrm{Mg}^{2+}$ e $\mathrm{Zn}^{2+}$ ) ou trivalentes $\left(\mathrm{Fe}^{3+}\right)$ têm efeito negativo (Wills \& McWhorter, 1985; Thelen et al., 1995). Supõese que os cátions bi e trivalentes sejam prejudiciais em razão da formação de estruturas 2:1 (duas moléculas de glifosato para cada cátion) ou 1:1, com significativa alteração estrutural da molécula. Em ambos os casos, a absorção do glifosato é prejudicada (Thelen et al., 1995; Mueller et al., 2006). Gauvrit (2003), Pratt et al. (2003) e Young et al. (2003) demonstraram maior eficácia do glifosato após adição de sulfato de amônio à calda preparada com água com altas concentrações de $\mathrm{Ca}^{2+} \mathrm{e}$ $\mathrm{Mg}^{2+}$. Há evidências de que a adição desse fertilizante à água de boa qualidade também melhora o desempenho do herbicida (Carvalho et al., 2008; Nurse et al., 2008).

A adição de fontes nitrogenadas à calda de glifosato também tem sido relacionada com a acidificação do meio. $\mathrm{O} \mathrm{pH}$ da calda interfere na atividade herbicida e na facilidade de penetração cuticular e solubilidade das moléculas (McCormick, 1990; Green \& Cahill, 2003). Para herbicidas ácidos fracos, como é o caso do glifosato, a redução do $\mathrm{pH}$ resulta em melhor eficácia, visto que moléculas menos ionizadas atravessam a cutícula e a membrana plasmática com maior facilidade (Nalewaja \& Matysiak, 1993). É possível que a pulverização com pressurização por $\mathrm{CO}_{2}$ também possa alterar a eficácia do glifosato, pois a reação do $\mathrm{CO}_{2}$ com a água acidifica a solução: $\mathrm{CO}_{2}+\mathrm{H}_{2} \mathrm{O} \leftrightarrow\left[\mathrm{H}_{2} \mathrm{CO}_{3}\right] \leftrightarrow \mathrm{H}^{+}+\mathrm{HCO}_{3}^{-}$ (McCormick, 1990).

Este trabalho foi desenvolvido com o objetivo de avaliar a eficácia no controle de plantas daninhas e a variação do $\mathrm{pH}$ de caldas de glifosato com o uso de diferentes concentrações do produto e de fertilizantes nitrogenados e após a utilização de pulverizador costal pressurizado por $\mathrm{CO}_{2}$.

\section{Material e Métodos}

O trabalho foi desenvolvido em Piracicaba, SP ( $22^{\circ} 42^{\prime} 30^{\prime \prime} \mathrm{S}, 47^{\circ} 38^{\prime} 0^{\prime \prime} \mathrm{W}$ e $546 \mathrm{~m}$ de altitude), entre abril e agosto de 2008, e contemplou um experimento em campo e quatro no Laboratório de Biologia de Plantas Daninhas da Escola Superior de Agricultura Luiz de Queiroz (USP-Esalq).

Em campo, o experimento foi realizado em área pertencente à Fazenda Areão, também da USP-Esalq, cujo solo foi classificado como Argissolo Vermelho eutroférrico de textura argilosa, $\mathrm{pH} 5,2$, com $28 \mathrm{~g} \mathrm{~kg}^{-1}$ de matéria orgânica e $60 \%$ de saturação por bases. A densidade total de plantas daninhas foi estimada em 120 plantas $\mathrm{m}^{-2}$, composta por $30 \%$ de guanxuma ( $S i d a$ spp.) em pré-florescimento, $15 \%$ de capim-amargoso(Digitariainsularis)emflorescimento, $20 \%$ de capim-rabo-de-raposa (Setaria geniculata) em florescimento, 20\% de capim-carrapicho (Cenchrus echinatus) em florescimento, $10 \%$ de apaga-fogo (Alternanthera tenella) em florescimento, e 5\% de outras espécies.

$\mathrm{O}$ delineamento experimental foi o de blocos ao acaso, com 11 tratamentos e três repetições. As parcelas usadas tinham $2,5 \times 4,0 \mathrm{~m}$, com $8 \mathrm{~m}^{2}$ de área útil. Foram aplicadas duas doses de glifosato $\left(360\right.$ e $720 \mathrm{~g} \mathrm{ha}^{-1} \mathrm{de}$ e.a.; Roundup Original), isoladas ou combinadas com duas concentrações de ureia $\left(2,5\right.$ e $\left.5,0 \mathrm{~g} \mathrm{~L}^{-1}\right)$ ou sulfato de amônio (7,5 e 15,0 $\left.\mathrm{g} \mathrm{L}^{-1}\right)$, além do tratamento testemunha, sem aplicação. As doses de glifosato foram fundamentadas nas recomendações de registro para as espécies de plantas daninhas (Rodrigues \& Almeida, 2005). Foram aplicados $200 \mathrm{~L} \mathrm{ha}^{-1}$ de calda.

A aplicação foi realizada no dia 15 de abril de 2008, das $10 \mathrm{~h} 40$ às $11 \mathrm{~h} 30$, quando os parâmetros meteorológicos médios foram: umidade relativa de $87,3 \%$; temperatura de $21,4^{\circ} \mathrm{C}$; céu encoberto por nuvens e ventos de $4,1 \mathrm{~km} \mathrm{~h}^{-1}$. A primeira chuva foi registrada em período superior a 48 horas depois da aplicação. Foi utilizado um pulverizador costal pressurizado por $\mathrm{CO}_{2}$, acoplado a uma barra de pulverização com largura útil de $2 \mathrm{~m}$, com quatro pontas do tipo jato plano, XR 110.02, espaçadas em $0,50 \mathrm{~m}$. As precipitações e a temperatura média diária do período em que o experimento esteve em campo estão apresentadas na Figura 1.

Aágua utilizada foi procedente de tratamento comum para distribuição pública, realizado na Esalq/USP, e o resultado de sua análise foi (em $\mathrm{mg} \mathrm{L}^{-1}$ ): cloreto, 26; nitrato, 11,5; sulfato, 68,3 ; fósforo, 0,01 ; sódio, 36,5 ; potássio, 4,8; cálcio, 38,8; magnésio, 2,7; ferro, 0,02; cobre, 0; manganês, 0,02; zinco, 0,09; alcalinidade $\left(2 \mathrm{CO}_{3}^{2-}+\mathrm{HCO}_{3}^{-}\right), 40,2$; nitrogênio amoniacal, 0,2 ; sedimentos em suspensão, 1; gás carbônico, 0,4; 
acidez $\left(\mathrm{CaCO}_{3}\right)$, 1; e dureza total $\left(\mathrm{CaCO}_{3}\right), 107,8$. Os demais parâmetros apresentaram os seguintes valores: $\mathrm{pH}$ 8,2; cor aparente, 0 PtCo; turbidez, 0 FTU; e condutividade elétrica (CE), $0,26 \mathrm{mS} \mathrm{cm}^{-1}$. O parâmetro dureza total foi calculado com base no equivalente de carbonato de cálcio $\left(\mathrm{CaCO}_{3}\right)$, segundo Franson (1995): 2,497 [Ca, $\left.\mathrm{mg} \mathrm{L}^{-1}\right]+4,118\left[\mathrm{Mg}, \mathrm{mg} \mathrm{L}^{-1}\right]$.

As variáveis avaliadas foram: controle percentual das plantas daninhas aos 14, 21 e 28 dias após a aplicação (DAA) e massa de matéria seca residual das plantas daninhas aos 28 DAA. O controle foi avaliado considerando a totalidade da comunidade infestante das parcelas, com uso de escala com variação entre $0 \mathrm{e}$ $100 \%$, em que zero representou a ausência de sintomas e 100 a morte das plantas (Sociedade Brasileira da Ciência das Plantas Daninhas, 1995). Para obtenção da massa de matéria seca, uma moldura de madeira de $0,5 \times 0,5 \mathrm{~m}$ foi lançada uma vez em área representativa de cada parcela. Todo o material vegetal presente na área da moldura foi cortado rente à superfície do solo e seco em estufa $\left(70^{\circ} \mathrm{C}\right)$ até massa constante.

Emlaboratório,os experimentos foram desenvolvidos em delineamento inteiramente casualizado, com três repetições. Nesses experimentos, foram avaliadas a variação do $\mathrm{pH}$ de caldas de glifosato após a adição de fertilizantes nitrogenados e a utilização de pulverizador costal pressurizado por $\mathrm{CO}_{2}$. Foi adotada a calda equivalente a $200 \mathrm{~L} \mathrm{ha}^{-1}$. A formulação comercial Roundup Original foi mantida como padrão de avaliação e o pH foi a única variável mensurada, por meio de medidor digital de $\mathrm{pH}$ da Tecnal, modelo TEC-3MP.

Os três primeiros experimentos foram desenvolvidos em béqueres de vidro com $200 \mathrm{~mL}$ de calda. Noprimeiro,

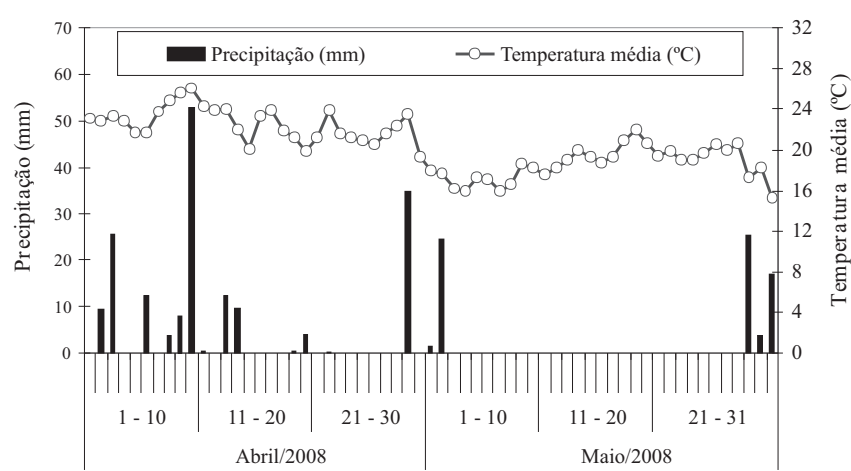

Figura 1. Temperatura média e precipitações diárias observadas no período de condução do experimento em campo. foi avaliado o efeito da concentração da solução com glifosato. Para tanto, foi adotado esquema de tratamento fatorial $7 \times 2$, em que sete foram as concentrações de glifosato $\left(0,2,5,5,10,20,40\right.$ e $80 \mathrm{~mL} \mathrm{~L}^{-1}$ de produto comercial) e duas foram as fontes de água utilizadas (deionizada e comum para distribuição pública). Cada calda foi agitada por $1 \mathrm{~min}$.

No segundo experimento, foi avaliado o efeito do sulfato de amônio no $\mathrm{pH}$ da calda, em esquema fatorial $5 \times 2$, no qual cinco foram as concentrações de sulfato de amônio $\left(0,2,5,5,10\right.$ e $\left.20 \mathrm{~g} \mathrm{~L}^{-1}\right)$ e duas as doses de glifosato (5 e $20 \mathrm{~mL}$ de produto comercial por litro).

No terceiro experimento, foi avaliado o efeito de cinco concentrações de ureia $\left(0,1,25,2,5,5\right.$ e $\left.10 \mathrm{~g} \mathrm{~L}^{-1}\right)$ no $\mathrm{pH}$ da calda de glifosato $(5 \mathrm{~mL}$ de produto comercial por litro).

No segundo e terceiro experimentos, foi utilizada água comum e as caldas foram agitadas por $3 \mathrm{~min}$.

Oquartoexperimentoobjetivouavaliarainterferência do pulverizador costal pressurizado por $\mathrm{CO}_{2}$ no $\mathrm{pH}$ da calda de glifosato. Foram empregados 12 tratamentos, semelhantes aos do experimento de campo, nos quais a maior dose de glifosato foi substituída por $1.440 \mathrm{~g} \mathrm{ha}^{-1}$, visando maior amplitude de resposta. As condições da experimentação foram semelhantes às utilizadas em campo, porém foi adotada uma única ponta, XR 110.02, e somente $50 \%$ da capacidade do reservatório de $2 \mathrm{~L}$ foi preenchida com calda. Este procedimento visou potencializar a mistura de gás carbônico na solução por meio de $1 \mathrm{~L}$ de espaço livre no reservatório. Alíquotas de $50 \mathrm{~mL}$ foram retiradas e o $\mathrm{pH}$ foi medido na calda original, imediatamente após a aplicação e após duas horas de repouso da calda pulverizada.

Inicialmente, todos os dados foram submetidos à análise da variância, a 5\% de probabilidade. Quando da significância do teste $F$, foi aplicado o teste de Scott-Knott, para comparação das médias dos fatores de tratamentos qualitativos (Scott \& Knott, 1974), também com $5 \%$ de probabilidade. Os níveis de fatores de tratamentos quantitativos foram ajustados por regressões logarítmicas ou polinomiais.

\section{Resultados e Discussão}

Houve efeito de tratamentos em todas as variáveis analisadas no experimento em campo (Tabela 1). Foi constatado efeito de doses de glifosato em que a aplicação de $720 \mathrm{~g} \mathrm{ha}^{-1}$ proporcionou controle sempre superior a $90 \%$ e diferente da pulverização de glifosato 
isolado a $360 \mathrm{~g} \mathrm{ha}^{-1}$. A adição de sulfato de amônio $\left(15 \mathrm{~g} \mathrm{~L}^{-1}\right)$ à calda elevou o controle obtido pela menor dose de glifosato, igualando-a à maior dose de glifosato isolado. No caso da ureia, somente foram observados efeitos benéficos aos 28 DAA com a adição de $5 \mathrm{~g} \mathrm{~L}^{-1}$ à menor dose do herbicida, com $96,7 \%$ de controle. Todos os tratamentos reduziram a massa de matéria seca de plantas daninhas em relação ao tratamento testemunha. Não houve diferença entre as doses de glifosato ou fontes nitrogenadas sobre essa variável (Tabela 1).

Os resultados obtidos nesse experimento estão em concordância com os relatados por Carvalho et al. (2008), que observaram incrementos de controle com a adição de até $10 \mathrm{~g} \mathrm{~L}^{-1}$ de sulfato de amônio à calda de glifosato e também não observaram efeito dos tratamentos sobre a massa de matéria seca.

Diversos trabalhos demonstram a maior eficácia do glifosato quando aplicado com sulfato de amônio. Donald (1988) concluiu que a adição de sulfato de amônio elevou a eficácia do glifosato no controle de Hordeum jubatum; Nalewaja \& Matysiak (1993) observaram maior controle de Triticum aestivum (planta-teste) com o uso do sulfato de amônio como antagonista de sais prejudiciaisà eficácia desteherbicida; Jordan et al. (1997) relataram melhor controle de Sida spinosa e Ipomoea hederacea var. intergriuscula; Pratt et al. (2003) avaliaram diversos adjuvantes para controle de Abutilon theophrasti com aplicação de glifosato e glufosinato de amônio e concluíram que nenhum foi superior ao sulfato de amônio $\left(20 \mathrm{~g} \mathrm{~L}^{-1}\right)$.
A maior eficácia do herbicida glifosato em presença do sulfato de amônio é atribuída à atividade do sulfato como antagonista de cátions presentes na água,

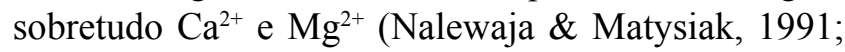
Thelen et al., 1995; Gauvrit, 2003). Porém, não há consenso quanto aos teores máximos a partir dos quais concentrações de cálcio e magnésio passam a reduzir a eficácia do glifosato. Mueller et al. (2006) relataram que concentrações superiores a 250 e $500 \mathrm{mg} \mathrm{L}^{-1}$ de cálcio e magnésio, respectivamente, reduzem a eficácia do herbicida. Por outro lado, Gauvrit (2003) observou menor eficácia de glifosato aplicado com $200 \mathrm{mg} \mathrm{L}^{-1}$ de cálcio, concentração considerada moderada.

A análise da água utilizada neste trabalho indicou baixos níveis de cálcio e magnésio, da ordem de 38,8 e $2,7 \mathrm{mg} \mathrm{L}^{-1}$, respectivamente. A aplicação do herbicida foi realizada de acordo com as recomendações agronômicas: não havia poeira sobre as folhas das plantas daninhas em razão da ocorrência de chuva na véspera, não houve chuva logo após a aplicação e as condições meteorológicas foram adequadas à atividade do herbicida (Figura 1) nos dias que sucederam a aplicação. Desta forma, pode-se considerar que a maior eficácia do glifosato, quando em presença de sulfato de amônio, esteve relacionada à penetração ou absorção celular facilitada do herbicida (Ruiter \& Meinen, 1996; Satchivi et al., 2000; Young et al., 2003).

A absorção e a metabolização de grande quantidade de íons amônio promove desequilíbrio eletroquímico no interior das células, o que estimula a extrusão de

Tabela 1. Controle percentual de plantas daninhas aos 14, 21 e 28 dias após aplicação (DAA) de 11 tratamentos herbicidas com adição das fontes nitrogenadas (FN) ureia e sulfato de amônio (SA) e massa de matéria seca aos 28 DAA, em condição de campo $^{(1)}$.

\begin{tabular}{|c|c|c|c|c|c|c|}
\hline \multirow[t]{2}{*}{ Tratamentos } & \multicolumn{2}{|c|}{ Doses } & \multicolumn{3}{|c|}{ Controle percentual (DAA) } & \multirow{2}{*}{$\begin{array}{c}\text { Massa de matéria } \\
\text { seca }\left(\mathrm{g} \mathrm{m}^{-2}\right)\end{array}$} \\
\hline & $\begin{array}{l}\text { Herbicida }^{(2)} \\
\left(\mathrm{g} \mathrm{ha}^{-1}\right)\end{array}$ & $\begin{array}{c}\mathrm{FN} \\
\left(\mathrm{g} \mathrm{L}^{-1}\right)\end{array}$ & 14 & 21 & 28 & \\
\hline Testemunha sem aplicação & - & - & $0,0 \mathrm{c}$ & $0,0 \mathrm{c}$ & $0,0 \mathrm{c}$ & $622,3 b$ \\
\hline Glifosato & 360 & - & $79,3 b$ & $83,7 \mathrm{~b}$ & $93,0 \mathrm{~b}$ & $205,3 a$ \\
\hline Glifosato + SA & 360 & 7,5 & $81,7 \mathrm{~b}$ & $89,3 b$ & $95,7 b$ & $188,8 \mathrm{a}$ \\
\hline Glifosato + SA & 360 & 15,0 & $91,3 \mathrm{a}$ & $94,0 \mathrm{a}$ & $98,3 \mathrm{a}$ & $240,3 a$ \\
\hline Glifosato + Ureia & 360 & 2,5 & $80,0 \mathrm{~b}$ & $87,7 \mathrm{~b}$ & $93,0 \mathrm{~b}$ & $225,5 \mathrm{a}$ \\
\hline Glifosato + Ureia & 360 & 5,0 & $83,3 b$ & $89,0 \mathrm{~b}$ & $96,7 \mathrm{a}$ & $188,4 \mathrm{a}$ \\
\hline Glifosato & 720 & - & $91,7 \mathrm{a}$ & $93,7 \mathrm{a}$ & $99,0 \mathrm{a}$ & $223,6 \mathrm{a}$ \\
\hline Glifosato + SA & 720 & 7,5 & $97,0 \mathrm{a}$ & $98,0 \mathrm{a}$ & $100,0 \mathrm{a}$ & $196,7 \mathrm{a}$ \\
\hline Glifosato + SA & 720 & 15,0 & $95,0 \mathrm{a}$ & $96,3 a$ & $98,7 \mathrm{a}$ & $179,1 \mathrm{a}$ \\
\hline Glifosato + Ureia & 720 & 2,5 & $92,7 \mathrm{a}$ & $97,0 \mathrm{a}$ & $99,3 a$ & $175,6 \mathrm{a}$ \\
\hline Glifosato + Ureia & 720 & 5,0 & $90,7 \mathrm{a}$ & $96,3 \mathrm{a}$ & $98,7 \mathrm{a}$ & $272,5 \mathrm{a}$ \\
\hline $\mathrm{F}_{\text {(Tratamento) }}$ & & & $142,561 * *$ & $161,770 * *$ & $348,411 * *$ & $4,574 * *$ \\
\hline $\mathrm{CV}(\%)$ & & & 4,94 & 4,58 & 3,09 & 17,80 \\
\hline
\end{tabular}


prótons $\left(\mathrm{H}^{+}\right)$para o apoplasto por meio de ATPases (Gronwald et al., 1993). Assim, a absorção celular facilitada de glifosato nesta condição tem sido explicada pela maior concentração de $\mathrm{H}^{+}$e pela consequente redução do pH no apoplasto. Em água, o glifosato se comporta como um ácido fraco, com ionização parcial e quatro valores de $\mathrm{pKa}$, dois com importância prática: 2,6 e 5,6 (Coutinho \& Mazo, 2005). Dessa forma, a acidificação do apoplasto favorece a presença de formas químicas de glifosato menos dissociadas, que atravessam mais facilmente a membrana plasmática (apolar). No interior da célula, o $\mathrm{pH}$ do citoplasma $(7,0-7,5)$ facilita nova ionização das moléculas, que ficam retidas na forma ativa, sem mecanismo de retorno ao ambiente intercelular (Gronwald et al., 1993; Briskin, 1994). Além disso, MacIsaac et al. (1991) comentam que a adição de sulfato de amônio à calda promove alteração na morfologia das gotas e atrasa ou previne a cristalização do glifosato na superfície foliar.

A redução do $\mathrm{pH}$ do apoplasto após a aplicação de herbicidas com sulfato de amônio é bem documentada na literatura científica. Contudo, comumente também são discutidos aspectos relacionados com a redução do pH da calda de pulverização. Neste trabalho, a menor concentração utilizada do glifosato já foi suficiente para a detecção de significativo efeito acidificante do produto sobre a água (Figura $2 \mathrm{~A}$ ). Em razão da reduzida variabilidade dos dados experimentais em condições de laboratório, foi possível observar diferenças significativas de $\mathrm{pH}$ entre as fontes de água utilizadas, em todas as diluições, contudo sem importância prática. Para concentrações de produto comercial superiores a $10 \mathrm{~mL} \mathrm{~L}^{-1}$, houve estabilização do $\mathrm{pH}$ da solução em 4,5.

Sempre que possível, menores volumes de calda devem ser usados, pois, para a mesma dosagem, proporcionam maiores concentrações de produto comercial na calda, o que resulta em valores de $\mathrm{pH}$ mais baixos, que são benéficos à ação do glifosato. Esta prática também facilita a rotina agrícola e contribui para a redução na proporção de cátions antagônicos ao herbicida, de forma que o controle tende a ser maximizado (Buhler \& Burnside, 1983; Ramsdale et al., 2003).

Não foi observada interação da dose de glifosato com as concentrações de sulfato de amônio. Esse fertilizante promoveu pequena acidificação da calda, da ordem de 0,2 unidade de $\mathrm{pH}$, na concentração de $20 \mathrm{~g} \mathrm{~L}^{-1}$ (Figura $2 \mathrm{~B}$ ), o que está em concordância com Green \& Cahill (2003). No entanto, essa acidificação tem pequena aplicabilidade prática, pois o $\mathrm{pH}$ alcançado pouco aproxima o $\mathrm{pH}$ da calda do próximo pKa de importância agronômica, de cerca de 2,6. A combinação de ureia e glifosato não alterou o $\mathrm{pH}$ da calda, que se manteve em 4,96 (Figura 2 C).

A utilização do pulverizador costal pressurizado por $\mathrm{CO}_{2}$ reduziu o $\mathrm{pH}$ da água pura, porém os efeitos nas caldas herbicidas foram pequenos e de pouca significância prática (Tabela 2). Os valores mais
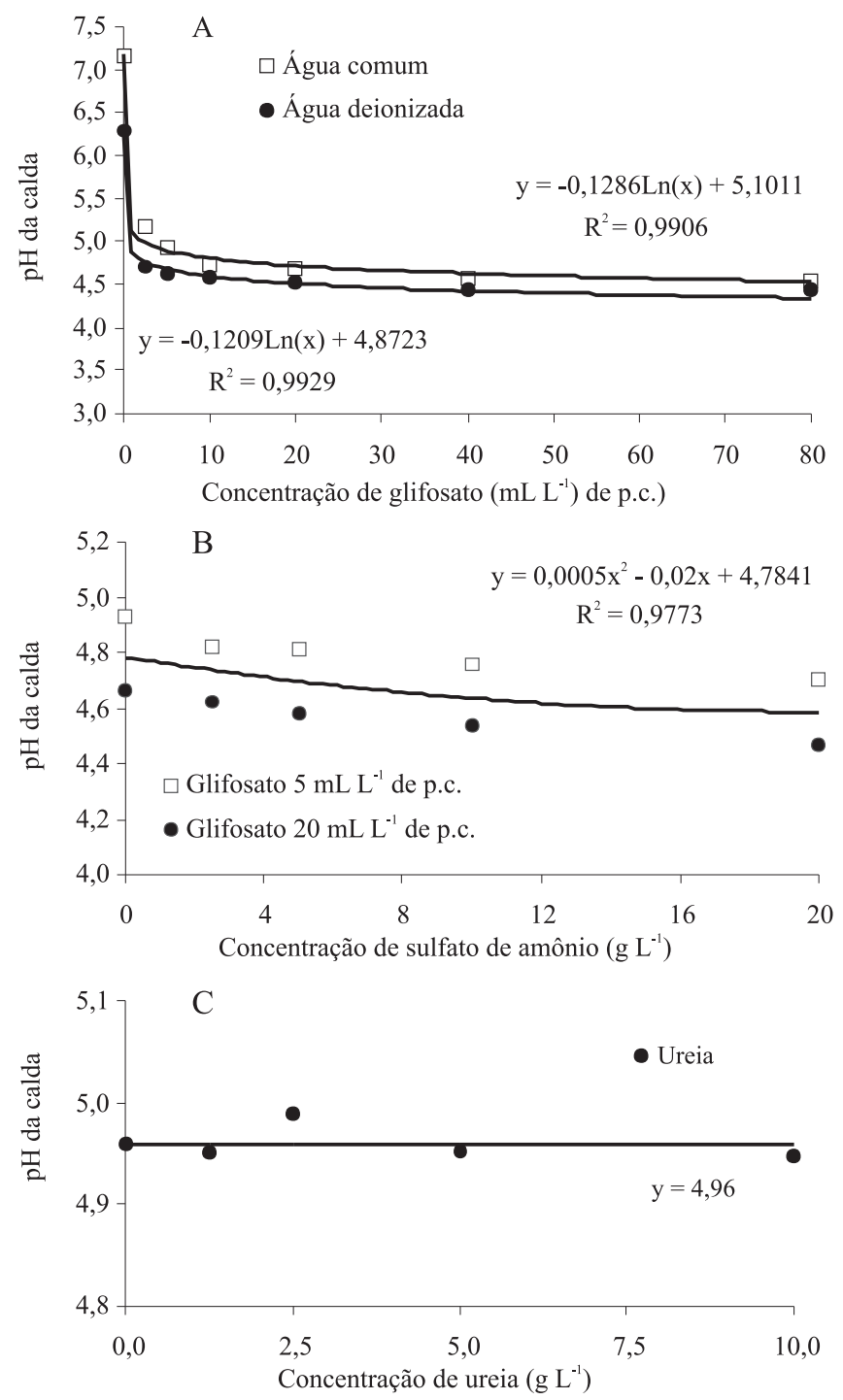

Figura 2. Variação no $\mathrm{pH}$ da calda do herbicida glifosato sob diferentes condições agronômicas $\left(\mathrm{T}=23,7^{\circ} \mathrm{C}\right)$ : A, glifosato (Roundup Original) diluído em água deionizada e em água comum tratada para distribuição pública; $\mathrm{B}$, adição de sulfato de amônio à calda de glifosato; $\mathrm{C}$, adição de ureia à calda de glifosato $\left(5 \mathrm{~mL} \mathrm{~L}^{-1}\right.$ de produto comercial). 
Tabela 2. Variação do pH da calda de pulverização do herbicida glifosato sob influência da adição de ureia e sulfato de amônio (SA) e da utilização de pulverizador costal (simulação) pressurizado por $\mathrm{CO}_{2}\left(\mathrm{~T}=20^{\circ} \mathrm{C}\right)^{(1)}$.

\begin{tabular}{|c|c|c|c|}
\hline \multirow[t]{2}{*}{ Tratamentos } & \multicolumn{3}{|c|}{ Condição da calda } \\
\hline & Original & $\begin{array}{c}\text { Após } \\
\text { simulação }\end{array}$ & $\begin{array}{l}\text { Após simulação } \\
\text { e repouso de } 2 \text { horas }\end{array}$ \\
\hline Água comum & $7,33 \mathrm{Fc}$ & $6,89 \mathrm{Ia}$ & $7,03 \mathrm{~Gb}$ \\
\hline Glifosato $^{(2)} 360 \mathrm{~g} \mathrm{ha}^{-1}$ & $5,00 \mathrm{Ea}$ & $5,08 \mathrm{Hb}$ & $4,96 \mathrm{Fa}$ \\
\hline Glifosato $360 \mathrm{~g} \mathrm{ha}^{-1}+\mathrm{SA} 7,5 \mathrm{~g} \mathrm{~L}^{-1}$ & $4,83 \mathrm{Db}$ & $4,74 \mathrm{Da}$ & $4,74 \mathrm{Da}$ \\
\hline Glifosato $360 \mathrm{~g} \mathrm{ha}^{-1}+\mathrm{SA} 15,0 \mathrm{~g} \mathrm{~L}^{-1}$ & $4,79 \mathrm{Cb}$ & $4,73 \mathrm{Da}$ & $4,74 \mathrm{Da}$ \\
\hline Glifosato $360 \mathrm{~g} \mathrm{ha}^{-1}+$ ureia $2,5 \mathrm{~g} \mathrm{~L}^{-1}$ & $4,98 \mathrm{~Eb}$ & $4,91 \mathrm{Ga}$ & $4,89 \mathrm{Ea}$ \\
\hline Glifosato $360 \mathrm{~g} \mathrm{ha}^{-1}+$ ureia $5,0 \mathrm{~g} \mathrm{~L}^{-1}$ & $4,99 \mathrm{~Eb}$ & $4,87 \mathrm{Fa}$ & $4,94 \mathrm{Fb}$ \\
\hline Glifosato $720 \mathrm{~g} \mathrm{ha}^{-1}$ & $4,83 \mathrm{Db}$ & $4,83 \mathrm{~Eb}$ & $4,77 \mathrm{Da}$ \\
\hline Glifosato $1.440 \mathrm{~g}$ ha & $4,66 \mathrm{Bb}$ & $4,58 \mathrm{Aa}$ & $4,66 \mathrm{Cb}$ \\
\hline Glifosato $1.440 \mathrm{~g} \mathrm{ha}^{-1}+\mathrm{SA} 7,5 \mathrm{~g} \mathrm{~L}^{-1}$ & $4,59 \mathrm{Aa}$ & $4,56 \mathrm{Aa}$ & $4,56 \mathrm{Aa}$ \\
\hline Glifosato $1.440 \mathrm{~g} \mathrm{ha}^{-1}+$ SA $15,0 \mathrm{~g} \mathrm{~L}^{-1}$ & $4,60 \mathrm{Ab}$ & $4,63 \mathrm{Bb}$ & $4,53 \mathrm{Aa}$ \\
\hline Glifosato $1.440 \mathrm{~g} \mathrm{ha}^{-1}+$ ureia $2,5 \mathrm{~g} \mathrm{~L}^{-1}$ & $4,69 \mathrm{Bb}$ & $4,68 \mathrm{Cb}$ & $4,61 \mathrm{Ba}$ \\
\hline Glifosato $1.440 \mathrm{~g} \mathrm{ha}^{-1}+$ ureia $5,0 \mathrm{~g} \mathrm{~L}^{-1}$ & $4,68 \mathrm{Ba}$ & $4,73 \mathrm{Db}$ & $4,65 \mathrm{Ca}$ \\
\hline $\mathrm{F}_{\text {(interação tratamentos } \mathrm{x} \text { calda) }}$ & & $31,961 * *$ & \\
\hline CV $(\%)$ & & 0,44 & \\
\hline
\end{tabular}

${ }^{(1)}$ Médias seguidas por letras iguais, maiúsculas nas colunas e minúsculas nas linhas, não diferem entre si pelo teste de Scott-Knott, a 5\% de probabilidade.

${ }^{(2)}$ Roundup Original, $360 \mathrm{~g} \mathrm{~L}^{-1}$ de equivalente ácido; volume de calda de $200 \mathrm{~L} \mathrm{ha}^{-1}$. ${ }^{* *}$ Significativo a $1 \%$ de probabilidade pelo teste $\mathrm{F}$.

baixos de $\mathrm{pH}$ foram observados com o uso da dose de $1.440 \mathrm{~g} \mathrm{ha}^{-1}$ de glifosato, pulverizado puro ou em combinação com sulfato de amônio. Em geral, a ureia não alterou o $\mathrm{pH}$ das caldas. McCormick (1990) também observou efeito acidificante na água após pressurização com $\mathrm{CO}_{2}$ ou adição de sulfato de amônio, contudo, nesse trabalho não foram incluídos herbicidas. No caso do glifosato, o produto comercial tem $\mathrm{pH}$ próximo de 4,6 e sua diluição promove efeito tamponante, o que torna suas caldas pouco passíveis de alteração no $\mathrm{pH}$ causada pela aplicação de fontes nitrogenadas.

A análise conjunta dos dados indica que os efeitos positivos da adição de sulfato de amônio em água de boa qualidade estão mais relacionados com particularidades fisiológicas da absorção do herbicida, principalmente quanto à acidificação do apoplasto. No caso da ureia, quando se observam efeitos benéficos, eles provavelmente são relacionados a danos físicos à cutícula foliar, o que facilita a penetração das moléculas (Durigan, 1992).

\section{Conclusões}

1. A adição de sulfato de amônio à calda herbicida proporciona maior eficácia do glifosato usado em baixa dosagem.

2. O sulfato de amônio causa pequena acidificação da calda herbicida, enquanto a ureia não altera o $\mathrm{pH}$.
3. $\mathrm{O}$ uso do pulverizador pressurizado por $\mathrm{CO}_{2}$ provoca pequena alteração no $\mathrm{pH}$ da calda de glifosato, sem consequências práticas sobre a eficácia desse herbicida.

\section{Agradecimentos}

Ao Conselho Nacional de Desenvolvimento Científico e Tecnológico, pela concessão de bolsas.

\section{Referências}

BRISKIN, D.P. Membranes and transport systems in plants: an overview. Weed Science, v.42, p.255-262, 1994.

BUHLER, D.D.; BURNSIDE, O.C. Effect of spray components on glyphosate toxicity to annual grasses. Weed Science, v.31, p.124-130, 1983.

CARVALHO, S.J.P. de; DIAS, A.C.R.; DAMIN, V.; NICOLAI, M.; CHRISTOFFOLETI, P.J. Glifosato aplicado com diferentes concentrações de ureia ou sulfato de amônio para dessecação de plantas daninhas. Pesquisa Agropecuária Brasileira, v.43, p.1501-1508, 2008.

CHRISTOFFOLETI, P.J.; LÓPEZ-OVEJERO, R.F. Dinâmica dos herbicidas aplicados ao solo na cultura da cana-de-açúcar. Piracicaba: BASF, 2005. 49p.

COUTINHO, C.F.B.; MAZO, L.H. Complexos metálicos com o herbicida glifosato: revisão. Química Nova, v.28, p.1038-1045, 2005.

DONALD, W.W. Established foxtail barley, Hordeum jubatum, control with glyphosate plus ammonium sulfate. Weed Technology, v.2, p.364-368, 1988. 
DURIGAN, J.C. Efeito de adjuvantes na calda e do estádio de desenvolvimento das plantas, no controle do capim-colonião (Panicum maximum) com glyphosate. Planta Daninha, v.10, p.39-44, 1992.

FRANSON, M.A.H. Standard methods for the examination of water and wastewater. 19.ed. Washington: American Public Health Association, 1995. 1074p.

GAUVRIT, C. Glyphosate response to calcium, ethoxylated amine surfactant, and ammonium sulfate. Weed Technology, v.17, p.799-804, 2003.

GREEN, J.M.; CAHILL, W.R. Enhancing the biological activity of nicosulfuron with $\mathrm{pH}$ adjusters. Weed Technology, v.17, p.338-345, 2003.

GRONWALD, J.W.; JOURDAN, S.W.; WYSE, D.L.; SOMERS, D.A.; MAGNUSSON, M.U. Effect of ammonium sulfate on absorption of imazethapyr by quackgrass (Elytrigia repens) and maize (Zea mays) cell suspension cultures. Weed Science, v.41, p.325-334, 1993.

JORDAN, D.L.; YORK, A.C.; GRIFFIN, J.L.; CLAY, P.A.; VIDRINE, P.R.; REYNOLDS, D.B. Influence of application variables on efficacy of glyphosate. Weed Technology, v.11, p.354-362, 1997.

MACISAAC, S.A.; PAUL, R.N.; DEVINE, M.D. A scanning electron microscope study of glyphosate deposits in relation to foliar uptake. Pesticide Science, v.31, p.53-64, 1991.

MCCORMICK, R.W. Effects of $\mathrm{CO}_{2}, \mathrm{~N}_{2}$ air and nitrogen salts on spray solution pH. Weed Technology, v.4, p.910-912, 1990.

MUELLER, T.C.; MAIN, C.L.; THOMPSON, M.A.; STECKEL, L.E. Comparison of glyphosate salts (isopropylamine, diammonium and potassium) and calcium and magnesium concentrations on the control of various weeds. Weed Technology, v.20, p.164-171, 2006.

NALEWAJA, J.D.; MATYSIAK, R. Optimizing adjuvants to overcome glyphosate antagonistic salts. Weed Technology, v.7, p.337-342, 1993.

NALEWAJA, J.D.; MATYSIAK, R. Salt antagonism of glyphosate. Weed Science, v.39, p.622-628, 1991.

NURSE, R.E.; HAMILL, A.S.; KELLS, J.J.; SIKKEMA, P.H. Annual weed control may be improved when AMS is added to below-label glyphosate doses in glyphosate-tolerant maize (Zea mays L.). Crop Protection, v.27, p.452-458, 2008.

PRATT, D.; KELLS, J.J.; PENNER, D. Substitutes for ammonium sulfate as additives with glyphosate and glufosinate. Weed Technology, v.17, p.576-581, 2003.

RAMSDALE, B.K.; MESSERSMITH, C.G.; NALEWAJA, J.D. Spray volume, formulation, ammonium sulfate, and nozzle effects on glyphosate efficacy. Weed Technology, v.17, p.589-598, 2003.

RODRIGUES, B.N.; ALMEIDA, F.S. Guia de herbicidas. 5.ed. Londrina, 2005. 592p.

RUITER, H. de; MEINEN, E. Adjuvant-increased glyphosate uptake by protoplasts isolated from quackgrass Elytrigia repens (L.) Nevski. Weed Science, v.44, p.38-45, 1996.

SATCHIVI, N.M.; WAX, L.M.; STOLLER, E.W.; BRISKIN, D.P. Absorption and translocation of glyphosate isopropylamine and trimethysulfonium salts in Abutilon theophrasti and Setaria faberi. Weed Science, v.48, p.675-679, 2000.

SCOTT, A.J.; KNOTT, M.A. Cluster analysis method for grouping means in the analysis of variance. Biometrics, v.30, p.507-512, 1974.

SOCIEDADE BRASILEIRA DA CIÊNCIA DAS PLANTAS DANINHAS. Procedimentos para instalação, avaliação e análise de experimentos com herbicidas. Londrina: SBCPD, 1995. 42p.

THELEN, K.D.; JACKSON, E.P.; PENNER, D. The basis for the hard-water antagonism of glyphosate activity. Weed Science, v.43, p.541-548, 1995.

TIMOSSI, P.C.; DURIGAN, J.C.; LEITE, G.J. Eficácia de glyphosate em plantas de cobertura. Planta Daninha, v.24, p.475-480, 2006.

WILLS, G.D.; MCWHORTER, C.G. Effect of inorganic salts on the toxicity and translocation of glyphosate and MSMA in purple nutsedge (Cyperus rotundus). Weed Science, v.33, p.755-761, 1985.

YOUNG,B.G.;KNEPP,A.W.;WAX,L.M.;HART, S.E. Glyphosate translocation in common lambsquarters (Chenopodium album) and velvetleaf (Abutilon theophrasti) in response to ammonium sulfate. Weed Science, v.51, p.151-156, 2003. 